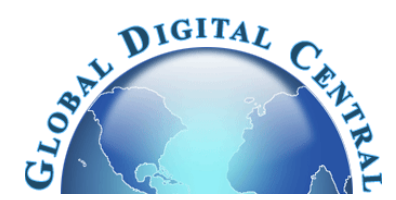

\title{
SLIP EFFECT ON HEAT AND MASS TRANSFER IN CASSON FLUID WITH CATTANEO-CHRISTOVE HEAT FLUX MODEL
}

\author{
P. Bala Anki Reddya , B. Mallikarjuna ${ }^{\mathrm{b}, *}$ K. Madhu Sudhan Reddy \\ a Department of Mathematics, School of Advanced Sciences, VIT University, Vellore, T.N., India \\ ${ }^{\mathrm{b}}$ Department of Mathematics, BMS College of Engineering, Bangalore, Karnataka-19, India
}

\begin{abstract}
In this paper, a mathematical model has been developed to analyze the double diffusive convective flow of Casson fluid over an inclined stretching sheet with Cattaneo-Christov Heat Flux model. The velocity slip is considered over the surface of the stretching sheet as well. The governing equations for the pertinent model are transformed into non-dimensional highly coupled nonlinear differential equations using similarity transformations. The implicit finite difference method is used to carry out the numerical results and presented the graphs for different values of the physical parameter, Casson fluid parameter, and thermal relation time parameter, chemical reaction parameter for the cases of assisting flow, opposing flow and blowing. The present results are compared with earlier existing results and found to be very good agreement. Increasing Casson fluid parameter retards the flow velocity and temperature fields and skin friction coefficient while enhance the concentration field, rate of heat and mass transfer. The fluid velocity and temperature fields, skin friction coefficients, heat and mass transfer rates are decreased with increase in thermal relation time while concentration profile enhanced. This type of study finds applications in industry and engineering fields like condensation processes, artificial fibers and heart valves and heat conduction in tissues etc. Increasing Casson fluid parameter causes to decelerates fluid velocity while accelerates temperature and concentration, skin friction coefficient, Nusselt number and Sherwood number as well. Increasing velocity slip parameter leads to reduce the fluid velocity and Nusselt \& Sherwood number while increases temperature and concentration distribution and skin friction coefficient values.
\end{abstract}

Keywords: Stretching Sheet; Casson Fluid; Cattaneo-Christov Heat Flux; Velocity Slip; Keller Box Method.

\section{INTRODUCTION}

In recent years the study of non-Newtonian fluid flow over a stretching surface has gained significant interest from scientists and researchers due to its wide range of applications in technology and industry. Such applications include the boundary layer over liquid film in condensation processes, artificial fibers, cooling of metallic sheets or electronic chips, food stuffs, biological solutions, glues, glass blowing, hot rolling, polymer extrusion from a dye, paper production, slurries, paints, wire drawing and many others. Many scientists and researchers Prasad et.al (2009), Mahantesh et al. (2010), Hayat et al. (2011), Nadeem et al. (2011), Sanjay anand et al. (2006) are explored the boundary layer flow over a stretching surface on various non-Newtonian models. The numerous non-Newtonian fluids are Casson fluids, Jeffrey fluid, micropolar fluids, power-law fluids, Rivlin- Ericksen fluids, viscoelastic fluids, Walter's liquid B fluids etc. Although various types of nonNewtonian fluid models are proposed to explain the behavior, one of the most significant types of non-Newtonian fluids is the Casson fluid. The Casson fluid is a plastic fluid and which yields shear stress in Constitutive equations. Some of the examples of Casson fluid model are coal in water, concentrated fruit juices, drilling operations, food processing, honey, jelly, metallurgy, manufacturing of pharmaceutical products, paints, synthetic lubricants, synovial fluids, sewage sludge, soup, tomato sauce and many others. Majority of researchers Fung (1984), Dash et al. (1996),
Nadeem et al. (2012), Hayat et al. (2011), Hayat et al. (2012), analyzed the Casson fluid flow over a stretching sheet. Recently, Bala Anki Reddy (2016) considered two- dimensional MHD convective boundary layer flow of a Casson fluid over an exponentially inclined permeable stretching surface in the presence of thermal radiation and chemical reaction. Very recently, investigate the steady two-dimensional magnetohydrodynamic boundary layer flow of a Casson fluid over an exponentially stretching surface in the presence of thermal radiation and chemical reaction was discussed by Bala Anki Reddy (2016). Nagendramma et al. (2018) studied 3D convective flow of a Casson nanofluid from slandering surface in a suspension of gyrotactic microorganisms with Cattaneo Christov heat flux.

Heat transfer dynamics is a significant fact in the nature which occurs due to temperature difference between two bodies or within the same body. The dynamics of heat transfer has enormous applications in engineering and industrial processes. For example, nuclear reactor cooling, wire drawing, cooper materials, cooling of electronic devices, heat conduction in tissues, refrigeration, heat pumps, energy production, etc. Heat conduction law explored by Fourier (1822) has been the origin to forecast the heat transfer behaviour in different practical situations. But it has a disadvantage that it produces a parabolic energy equation for the temperature field, by which the initial disturbance is instantly experienced by the medium under observation. In literature it is named as "Paradox of heat conduction". To get better of this, Cattaneo (2011) modified the Fourier's law of heat conduction by including the relaxation time for heat flux, which allows the transport of heat via propagation of thermal waves with finite speed. Later, Christov (2009) further modified

*Corresponding Author. Email: mallikarjuna.jntua@gmail.com, mallikarjunab.maths@bmsce.ac.in 
the Cattaneo model by including thermal relaxation time along with Oldroyd's upper-convected derivatives in order to achieve the materialinvariant formulation. This alteration in literature is recognized as Cattaneo- Christov heat flux model. Han et al. (2014) suggested a comparison of Fourier's Law and the Cattaneo-Christov heat flux model on a stretched boundary layer flow with Maxwell fluid. Mustafa (2015) suggested the uniqueness of Cattaneo-Christov heat flux in the rotating flow of Maxwell fluid over a linear stretching sheet. Cattaneo-Christov heat flux model is imposed to disclose the heat transfer characteristics of variable thermal conductivity viscoelastic fluid over a stretching sheet with variable thickness was investigated by Hayat et al. (2015). Very recently, Hayat et al. (2016) discussed the convective flow of two viscoelastic fluid past a linear stretching sheet with Cattaneo-Christov heat flux.

To the best of author's knowledge, no one has discussed so far the Cattaneo-Christov heat flux model on the Casson fluid flow over an exponentially stretching surface. Hence, our motivation is to discuss the Cattaneo-Christov heat flux model for the magnetohydrodynamic flow of a Casson fluid over an exponentially stretching surface with chemical reaction. The slip velocity condition is also considered in this model. The numerical solutions are obtained by using implicit finite difference method. The numerical solutions obtained are then compared with those reported by Bala Anki Reddy (2016), Mukhopadhyay et.al (2013), Ishak (2011) for the skin friction coefficient and Nusselt number in the limiting case. Excellent agreement is achieved.

\section{MATHEMATICAL FORMULATION}

Consider two-dimensional flow of an incompressible viscous electrically conducting Casson fluid over an exponentially permeable stretching sheet which is inclined with an acute angle $\alpha$ to the vertical. The $x$-axis is taken along the stretching surface in the direction of the motion while the $y$-axis is perpendicular to the surface which is shown in Fig.1.

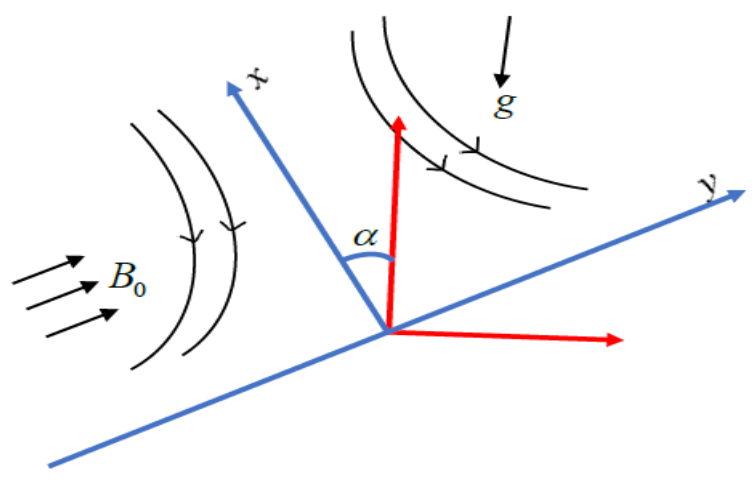

Fig. 1 Physical Configuration and Coordinate System

Stretching surface has the exponential velocity, $U=U_{0} e^{\frac{x}{L}}$ the temperature distribution $T_{w}=T_{\infty}+T_{0} e^{\frac{m x}{2 L}}$ and the concentration distribution $C_{w}=C_{\infty}+C_{0} e^{\frac{n x}{2 L}}$ where $U_{0}$ is the reference velocity, $T_{0}$ is the reference temperature, $C_{0}$ is the reference concentration, $m$ is the temperature exponent, $n$ is the concentration exponent and $\mathrm{L}$ is the reference length. A variable magnetic field $B=B_{0} e^{\frac{x}{2 L}}$ is applied normal to the sheet, where $B_{0}$ is a constant.

We assume that the rheological equation of state for an isotropic and incompressible flow of a Casson fluid is as

$$
\tau_{i j}=\left\{\begin{array}{l}
2\left(\mu_{B}+P_{y} / \sqrt{2 \pi}\right) e_{i j}, \pi>\pi_{c} \\
2\left(\mu_{B}+P_{y} / \sqrt{2 \pi}\right) e_{i j}, \pi<\pi_{c}
\end{array}\right.
$$

where $\mu_{B}$ is the plastic dynamic viscosity of the non-Newtonian fluid, $P_{y}$ is the yield stress of the fluid, $\pi=e_{i j} e_{i j}, e_{i j}$ is the $(i, j)^{\text {th }}$ component of the deformation rate and $\pi_{c}$ is the critical value of this product based on the non-Newtonian model.

The continuity, momentum, energy and concentration equations governing such type of flow can be written as

$$
\begin{aligned}
& \frac{\partial u}{\partial x}+\frac{\partial v}{\partial y}=0, \\
& u \frac{\partial u}{\partial x}+v \frac{\partial u}{\partial y}=-\frac{1}{\rho} \frac{\partial p}{\partial x}+v\left(1+\frac{1}{\beta}\right)\left(\frac{\partial^{2} u}{\partial x^{2}}+\frac{\partial^{2} u}{\partial y^{2}}\right)-\frac{\sigma B^{2}}{\rho} u \pm g \beta_{T}\left(T-T_{\infty}\right) \cos \alpha
\end{aligned}
$$

$u \frac{\partial v}{\partial x}+v \frac{\partial v}{\partial y}=-\frac{1}{\rho} \frac{\partial p}{\partial y}+v\left(1+\frac{1}{\beta}\right)\left(\frac{\partial^{2} u}{\partial x^{2}}+\frac{\partial^{2} u}{\partial y^{2}}\right)$

$\rho c_{p}\left(u \frac{\partial T}{\partial x}+v \frac{\partial T}{\partial y}\right)=-\nabla \cdot q$

$u \frac{\partial C}{\partial x}+v \frac{\partial C}{\partial y}=D \frac{\partial^{2} C}{\partial y^{2}}-\Gamma\left(C-C_{\infty}\right)$.

Subject to the boundary conditions:

$$
\begin{aligned}
& u=U+N \mu\left(1+\frac{1}{\beta}\right) \frac{\partial u}{\partial y}, v=-V(x), T=T_{w}(x)=T_{\infty}+T_{0} e^{\frac{m x}{2 L}}, \\
& C=C_{w}(x)=C_{\infty}+C_{0} e^{\frac{n x}{2 L}} \text { at } y=0 \\
& u \rightarrow 0, T \rightarrow T_{\infty}, C \rightarrow C_{\infty} \text {, as } y \rightarrow \infty .
\end{aligned}
$$

where $u$ and $v$ are the velocity components in the $x$ and $y$ directions respectively, $v$ is the kinematic viscosity, $\rho$ is the density of the fluid, $\beta=\frac{\mu_{B} 2 \pi_{c}}{p_{y}}$ is the Casson parameter, $\sigma$ is the electrical conductivity, $g$ acceleration due to gravity, $\beta_{T}$ coefficient of thermal expansion, $\beta^{*}$ coefficient of solutal expansion, $\mathrm{T}$ is the temperature, $T_{\infty}$ is the temperature of the ambient fluid, $C$ is the concentration, $C_{\infty}$ is the concentration of the ambient fluid, $\alpha$ is the angle of inclination, $c_{p}$ is the specific heat at constant pressure, $D$ is the mass diffusion coefficient, $N=N_{1} e^{\frac{-x}{2 L}}$ is the velocity slip factor and the reaction rate is in the form of $\Gamma=k_{0} e^{\frac{x}{L}}$ and $q$ is the heat flux which satisfies the following relationship:

$q+\lambda\left(\frac{\partial q}{\partial t}+V . \nabla q-q . \nabla V+(\nabla . V) q\right)=-k \nabla T$

Here $\lambda$ is the relaxation time of heat flux, $k$ is the thermal conductivity of the fluid and $V$ is the velocity vector. Eliminating $q$ from Eqs. (4) and (7) gives:

$u \frac{\partial T}{\partial x}+v \frac{\partial T}{\partial y}+\lambda\left(\begin{array}{l}u^{2} \frac{\partial^{2} T}{\partial x^{2}}+v^{2} \frac{\partial^{2} T}{\partial y^{2}}+2 u v \frac{\partial^{2} T}{\partial x \partial y}+u \frac{\partial u}{\partial x} \frac{\partial T}{\partial x} \\ +v \frac{\partial v}{\partial y} \frac{\partial T}{\partial y}+u \frac{\partial v}{\partial x} \frac{\partial T}{\partial y}+v \frac{\partial u}{\partial y} \frac{\partial T}{\partial x}\end{array}\right)=\alpha \frac{\partial^{2} T}{\partial y^{2}}$ 


$$
\begin{aligned}
& \eta=\left(\frac{U_{0}}{2 v L}\right)^{\frac{1}{2}} e^{\frac{x}{2 L}} y, u=U_{0} e^{\frac{x}{L}} f^{\prime}(\eta), v=-\sqrt{\frac{v U_{0}}{2 L}} e^{\frac{x}{2 L}}\left(f(\eta)+\eta f^{\prime}(\eta)\right), \\
& \theta=\frac{T-T_{\infty}}{T_{w}-T_{\infty}}, \phi=\frac{C-C_{\infty}}{C_{w}-C_{\infty}}
\end{aligned}
$$

The pressure outside the boundary layer in quiescent part of flow is constant and the flow occurs only due to the stretching of the sheet and hence the pressure gradient can be neglected. Considering the usual boundary layer approximations, $u>>v, \frac{\partial u}{\partial y}>>\frac{\partial u}{\partial x}, \frac{\partial v}{\partial y}, \frac{\partial v}{\partial y}$, the momentum equation in $y$-direction reduces to $\frac{\partial p}{\partial y}=0$. Now substituting (9) into the Equations (2), (5) and (8), we get the following set of ordinary differential equations

$\left(1+\frac{1}{\beta}\right) f^{\prime \prime \prime}+f f^{\prime \prime}-2\left(f^{\prime}\right)^{2}-H f^{\prime} \pm 2 \lambda_{1} \theta \cos \alpha+2 \delta \phi \cos \alpha=0$

$\frac{1}{\operatorname{Pr}} \theta^{\prime \prime}+f \theta^{\prime}+\lambda_{2}\left(m f f^{\prime \prime} \theta-m(2+m)\left(f^{\prime}\right)^{2} \theta+(1+2 m) f f^{\prime} \theta^{\prime}-f^{2} \theta^{\prime \prime}\right)=0$

$\phi^{\prime \prime}+S c\left(f \phi^{\prime}-n f^{\prime} \phi\right)-S c \gamma \phi=0$.

with the boundary conditions

$$
\begin{aligned}
& f=S, f^{\prime}=1+S_{v}\left(1+\frac{1}{\beta}\right) f^{\prime \prime}(0), \theta=1, \phi=1 \quad \text { at } \eta=0 \\
& f^{\prime} \rightarrow 0, \theta \rightarrow 1, \phi \rightarrow 1 \text { as } \eta \rightarrow \infty
\end{aligned}
$$

Where the prime denotes differentiation with respect to $\eta, H=\frac{2 \sigma B_{0}{ }^{2} L}{\rho U_{0}}$ is the magnetic parameter, $G r=\frac{g \beta_{T}\left(T_{w}-T_{\infty}\right) L x^{2}}{v^{2}}$ is the local Grashof number, $\lambda_{1}=\frac{G r}{\operatorname{Re}_{x}{ }^{2}}$ is the buoyancy parameter, $G c=\frac{g \beta^{*}\left(\mathrm{C}_{w}-C_{\infty}\right) L x^{2}}{v^{2}}$ is the local solutal Grashof number, $\delta=\frac{G c}{\operatorname{Re}_{x}^{2}}$ is the solutal buoyancy parameter, $\operatorname{Pr}=\frac{v}{\alpha}$ is the Prandtl number, $\lambda_{2}=\frac{\lambda U_{0} e^{\frac{x}{L}}}{L}$ is the thermal relaxation time, $S c=\frac{v}{D}$ is the Schmidt number, $\gamma=\frac{2 L k_{0}}{U_{0}}$ is thechemical reaction parameter, $S=V_{0} \sqrt{\frac{2 L}{U_{0} v}}>0($ or $<0)$ is the suction (or blowing) and $S_{v}=N_{1} \rho \sqrt{\frac{v U_{0}}{2 L}}$ is the velocity slip. Also, + sign and sign in Eq. (10) correspond to assisting and opposing buoyant flows respectively. It may be noted that when $\lambda=0$ in Eq. (8), the problem will be reduced to Fourier's heat conduction law.

The quantities of physical interest in this problem are the skin-friction coefficient, heat transfer rate and mass transfer, which are defined as

$$
C_{f}=\frac{2 \tau_{w}}{\rho U_{0}^{2} e^{\frac{2 x}{L}}}, N u_{x}=\frac{x q_{w}}{k\left(T_{w}-T_{\infty}\right)} S h_{x}=\frac{x J_{w}}{D\left(C_{w}-C_{\infty}\right)} .
$$

The surface shear stress $\tau_{w}$, surface heat flux $q_{w}$ and mass flux $J_{w}$ are given by

$$
\tau_{w}=\mu\left(\frac{\partial u}{\partial y}\right)_{y=0}, q_{w}=-k\left(\frac{\partial T}{\partial y}\right)_{y=0} \text { and } J_{w}=-D\left(\frac{\partial C}{\partial y}\right)_{y=0} .
$$

Substituting (10) and (17) into Equation (16), we get

$$
\begin{aligned}
& \frac{C_{f} \sqrt{\operatorname{Re}_{x} / 2}}{\sqrt{x / L}}=\left(1+\frac{1}{\beta}\right) f^{\prime \prime}(0), \frac{N u_{x}}{\sqrt{\operatorname{Re}_{x} / 2 \sqrt{x / L}}}=-\theta^{\prime}(0) \text { and } \\
& \frac{S h_{x}}{\sqrt{\operatorname{Re}_{x} / 2 \sqrt{x / L}}}=-\phi^{\prime}(0) .
\end{aligned}
$$

where $\operatorname{Re}_{x}=\frac{x U_{0} e^{\frac{x}{L}}}{v}$ is the local Reynolds number. The above Skinfriction coefficient, local Nusselt number and Sherwood number shows that its variation depends on the variation of the factors $f^{\prime \prime}(0),-\theta^{\prime}(0)$ and $-\phi^{\prime}(0)$ respectively.

\section{METHOD OF SOLUTION}

The set of equations (10) - (12) with conditions (13) are solved using implicit finite difference method with Keller box scheme, which gives second order accuracy. For the detail information of this method one can refer to Cebeci and Bradshaw (1984) and Bhuvanavijaya et.al (2016). The results are strongly dependent on the number of gird points in $\eta$ directions. $\Delta \eta$ value is to be chosen as 0.01 after some trails for $\Delta \eta=0.1,0.01,0.001 . \eta_{\max }$ is to be chosen as an adequately large value such that the conditions are satisfied. Grid independence has been obtained in the programming. The developed code is run in MATLAB ${ }^{\circledR}$. In order to validate the results comparison has been done with available existing results by Mukhopadhyay et.al (2013), Ishak (2011), and Bala Anki Reddy (2016) in the absence of concentration equations, Hartmann number, Casson fluid parameter, thermal and solutal buoyancy parameters, Schmidt number, suction parameter and velocity slip, as shown in table- 1 . The obtained results are correlated.

Table-1: Nusselt number values for various values of Pr for Newtonian fluid with $S=0$.

\begin{tabular}{|l|l|l|l|l|}
\hline Pr & $\begin{array}{l}\text { Mukhopadhyay } \\
\text { et.al (2013) }\end{array}$ & $\begin{array}{l}\text { Ishak } \\
(2011)\end{array}$ & $\begin{array}{l}\text { Bala Anki } \\
\text { Reddy (2016) }\end{array}$ & $\begin{array}{l}\text { Present } \\
\text { values }\end{array}$ \\
\hline 1 & 0.9547 & 0.9548 & 0.95477 & 0.954723 \\
\hline 3 & 1.8691 & 1.8691 & 1.86916 & 1.868775 \\
\hline 10 & 3.6603 & 3.6604 & 3.66038 & 3.660501 \\
\hline
\end{tabular}

\section{RESULTS AND DISCUSSIONS}

The solutions for the equations are carried out for the fluid velocity $\left(f^{\prime}\right)$, temperature $(\theta)$ and concentration $(\phi)$ profiles as presented in the figures (1)-(22) for various values of the physical parameters. Throughout the calculations we fixed the parameter $\mathrm{H}=0.5, \operatorname{Pr}=0.7$,

$\mathrm{Sc}=0.3, a=0.5, b=0.5, \alpha=\frac{\pi}{4}, \lambda_{1}=1, \lambda_{2}=0.5, \beta=1, \delta=0.5, \mathrm{~Sv}=0.5$ and $\mathrm{S}=1$ unless otherwise specified.

Figs. 2-4 represent profiles of flow velocity, temperature and concentration for different values of Casson fluid parameter $(\beta)$. The Casson fluid parameter $\beta=\frac{\mu_{B} 2 \pi_{c}}{p_{y}}$ is boasted in shear stress term in momentum equations (10) and in the velocity slip boundary condition (13). If $p_{y}$ tends to zero that is $\beta$ reaches to infinity, the term $\left(1+\frac{1}{\beta}\right)$ becomes unity in the eqns. (10) and (13), therefore the problem becomes Newtonian fluid case. Increasing $\beta$ implies decreasing in yield stress in 


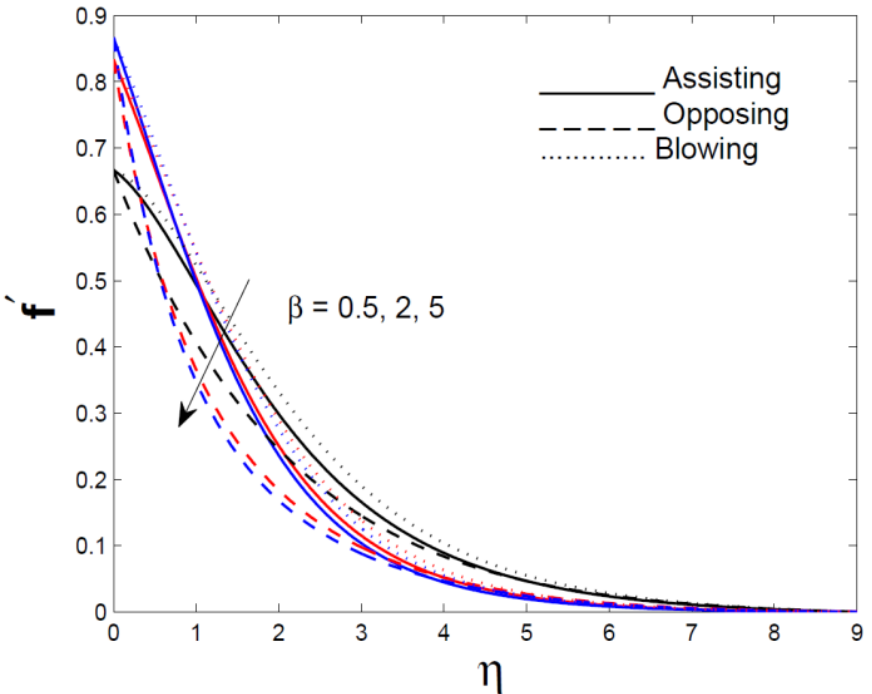

Fig. 2 Velocity Profile for different values of Casson parameter $(\beta)$

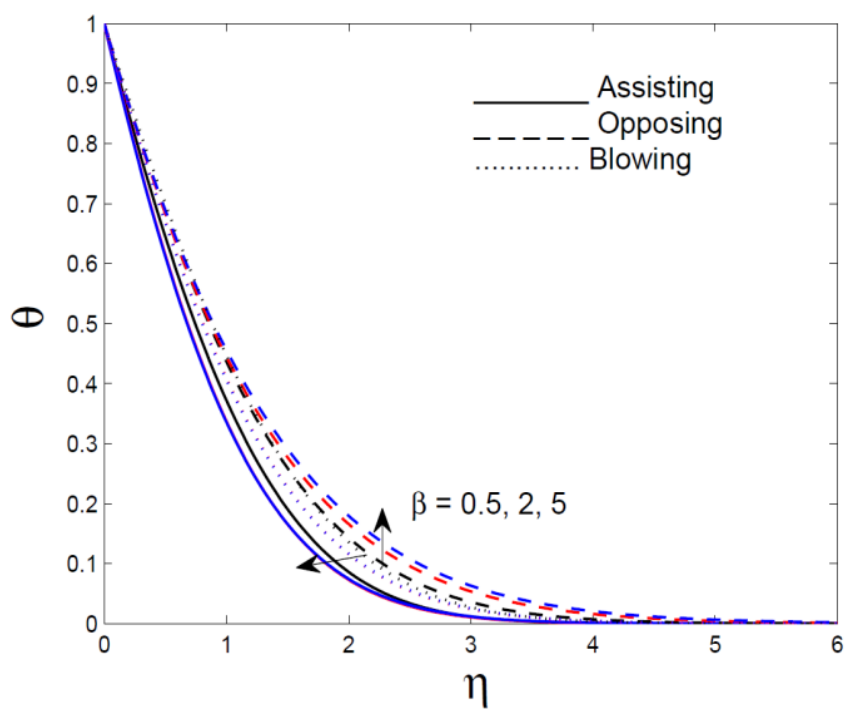

Fig. 3: Temperature distribution for different values of Casson parameter $(\beta)$

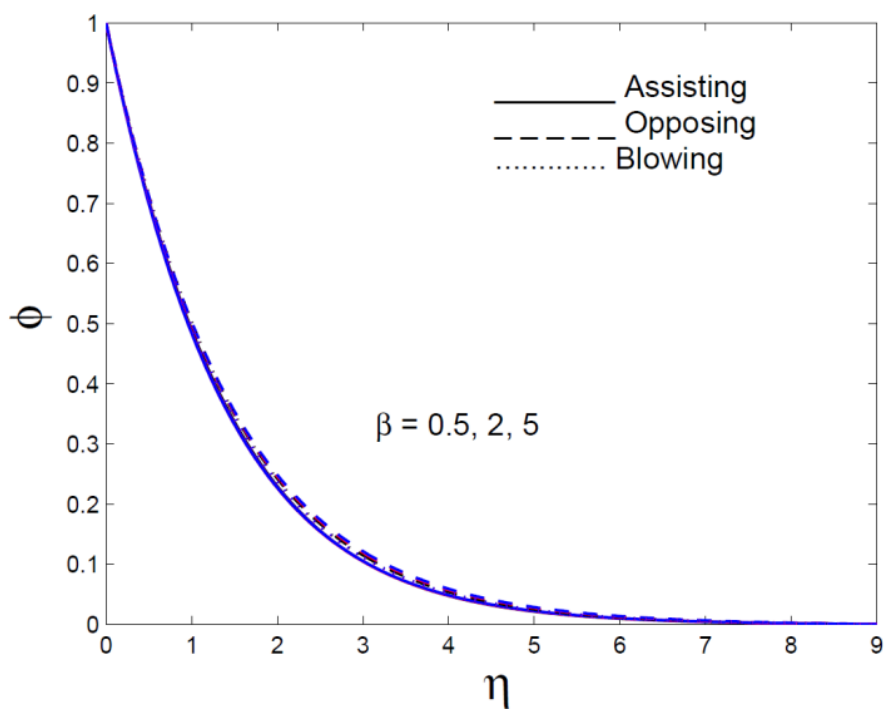

Fig. 4 Concentration distribution for different values of Casson parameter $(\beta)$

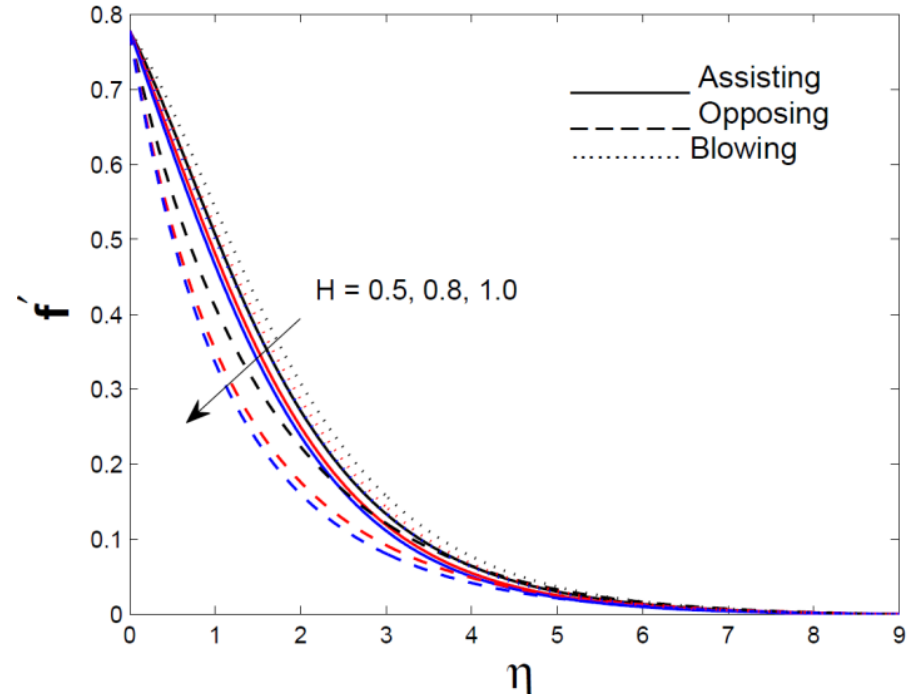

Fig. 5 Velocity profile for different values of Magnetic parameter $(\mathrm{H})$

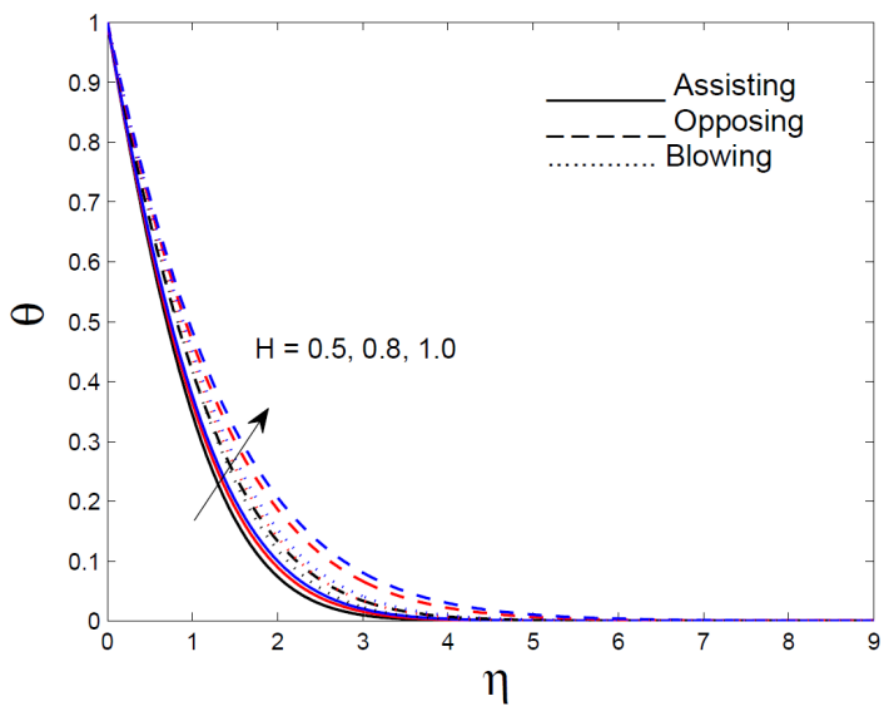

Fig. 6: Temperature distribution for different values of Magnetic parameter $(\mathrm{H})$

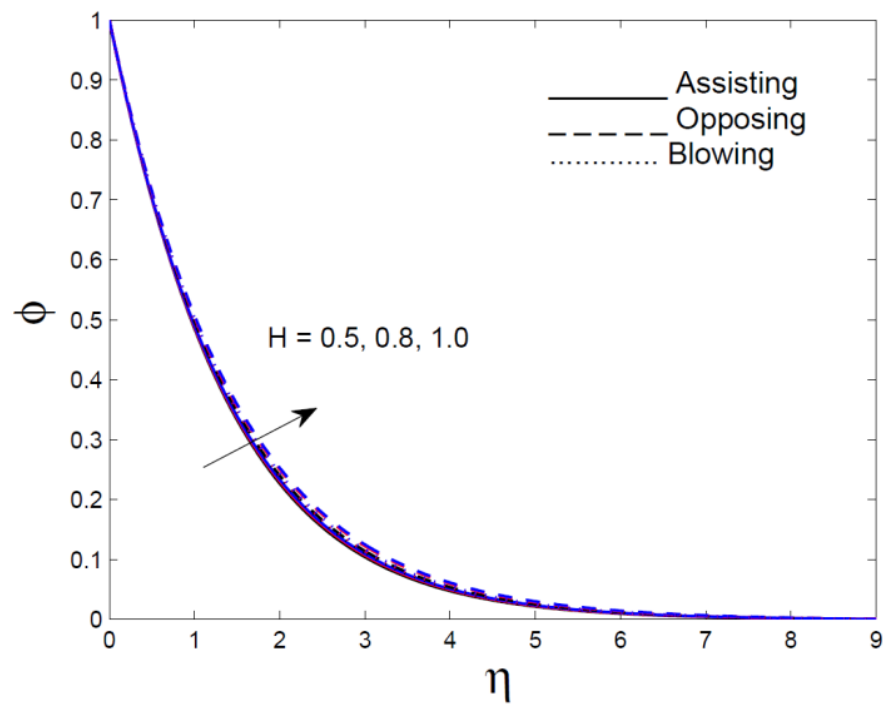

Fig. 7 Concentration distribution for different values of Magnetic parameter $(\mathrm{H})$ 
momentum equation due to which the fluid flow velocity facilitates effectively. Therefore the flow velocity increases near the wall and reduces at far from surface for the cases of assisting, opposing and blowing (fig.2). Temperature distribution decreases as increase in $\beta$ for the case of assisting and blowing flows but increases for the case of opposing flows as shown in fig.3. Casson parameter does not influence effectively in thermal boundary layer equations due to not arise in energy equation and thermal boundary condition. Indirectly it is influenced via coupling momentum and energy equations. With this reason concentration distribution also therefore increases sufficiently with increase in $\beta$ for the case of opposing flows but reduces for the cases of assisting and blowing flows (fig. 4). Overall, velocity and temperature boundary layer thickness reduced for larger values of $\beta$ whereas concentration boundary layer thickness increased. The present results concur with those presented by Ramachandraprasad et.al (2013) and Bala Anki Reddy (2016).

Figs. 5-7 represent flow velocity, temperature and concentration profiles for various values of Hartmann number $(\mathrm{H})$. As increase in Hartmann number, accelerated the Lorentz force which produce the resistance to the fluid flow causes to reduce velocity profile for all the cases of assisting, opposing and blowing. Thus the hydrodynamic boundary layer thickness is reduced (fig. 5). A very strong enhancement in temperature field as shown in fig. 6 is generated within the boundary layer regime for all cases of assisting, opposing and blowing. Maximized temperature is noticed at surface $(\eta=0)$ of stretching sheet and minimized in the ambient $\operatorname{stream}(\eta=8)$. The thickness of thermal boundary layer therefore increased with increase in $\mathrm{H}$. The thickness of the solutal boundary layer enhanced as well, i.e., accelerates the concentration profile as increase in $\mathrm{H}$ for all cases of assisting, opposing and blowing.

Figs. 8-10 depict flow characteristics velocity, temperature and concentration profiles for different values of solutal buoyancy parameter $(\delta)$. The parameter $\delta=G c / \operatorname{Re}_{x}{ }^{2}$ is the ratio of solutal Grashof number and Reynolds number. Increasing $\delta$ implies Reynolds number dominates the Grashof number inversely which cause to enhance velocity field indicating inertia forces influenced over viscous forces. These found to enhance velocity, and hence to accelerate thickness of momentum boundary layer for all cases of assisting, opposing and blowing with increase in $(\delta)$. It is observed from figs. 9 and 10 that thermal and concentration boundary layer thickness is lesser with the reason of depreciation of temperature and concentration distributions for all cases of assisting, opposing and blowing.

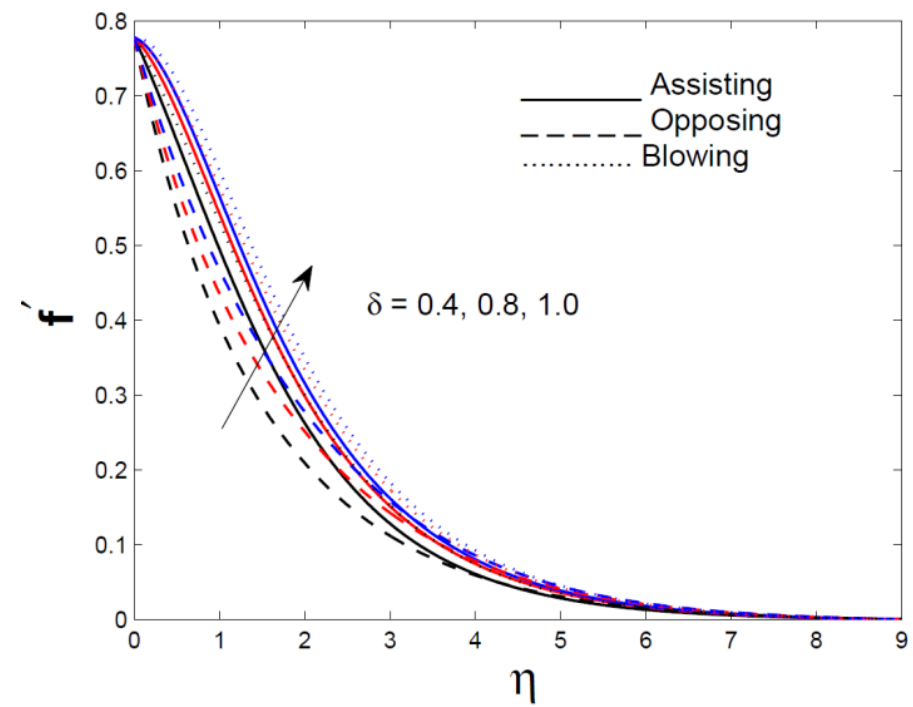

Fig. 8 Velocity profile for different values of solutal buoyancy parameter $(\delta)$

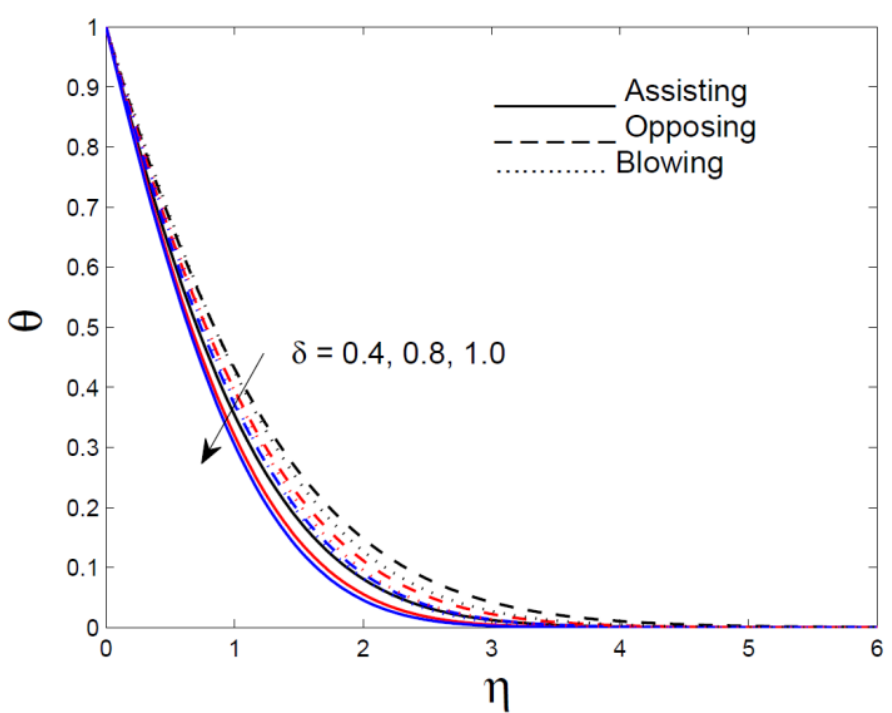

Fig. 9 Temperature distribution for different values of solutal buoyancy parameter $(\delta)$

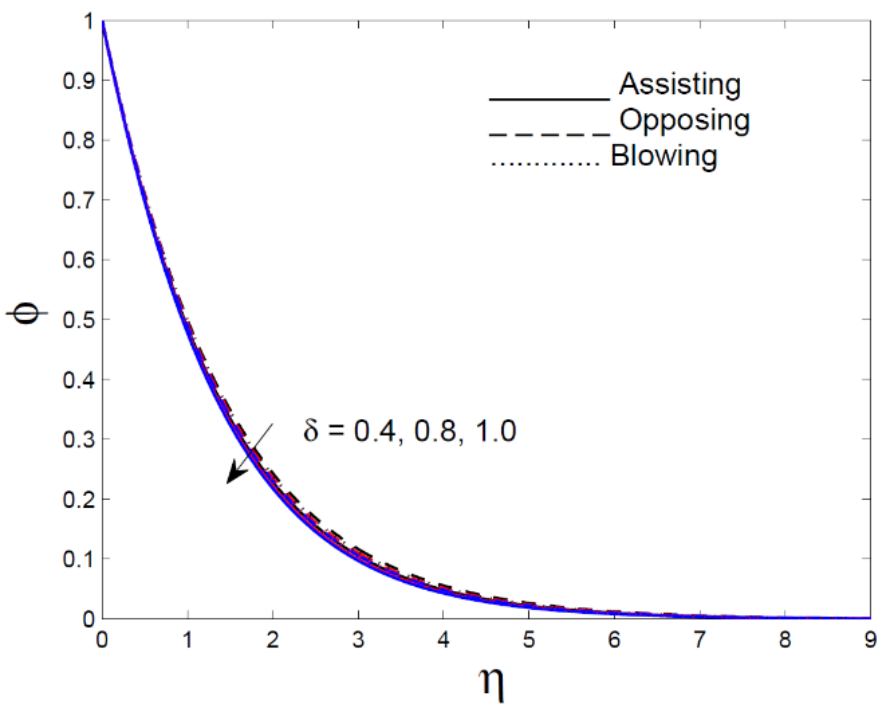

Fig. 10 Concentration distribution for different values of solutal buoyancy parameter $(\delta)$

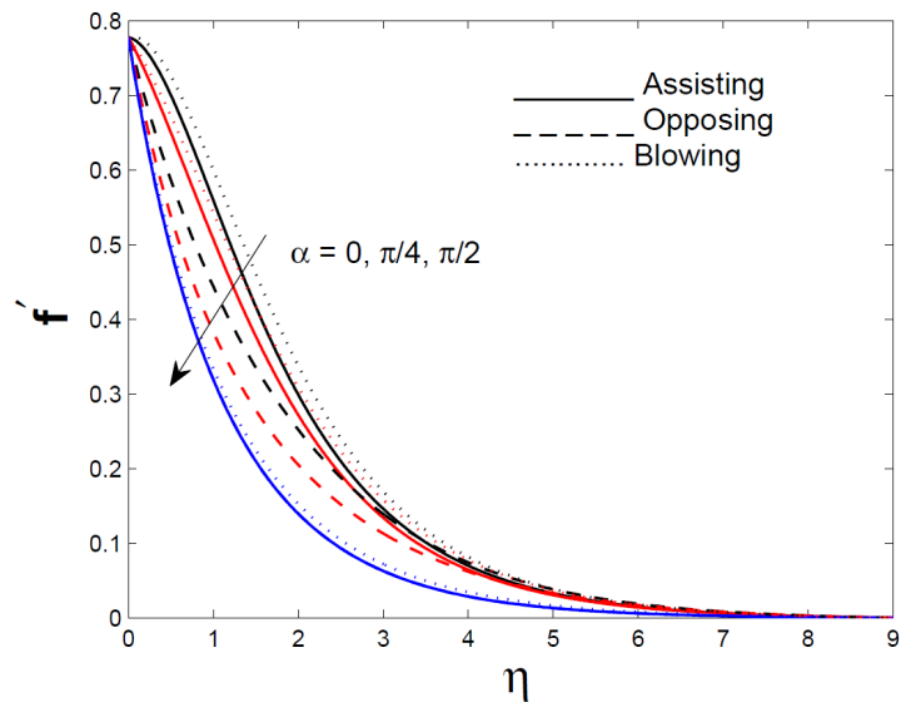

Fig. 11 Velocity profile for different values of angle of inclination $(\alpha)$ 


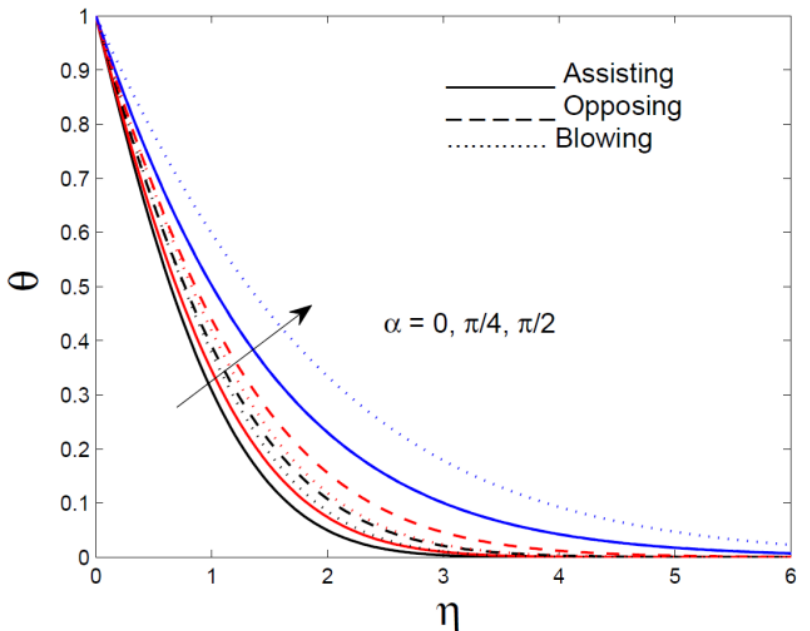

Fig. 12: Temperature distribution for different values of angle of inclination $(\alpha)$

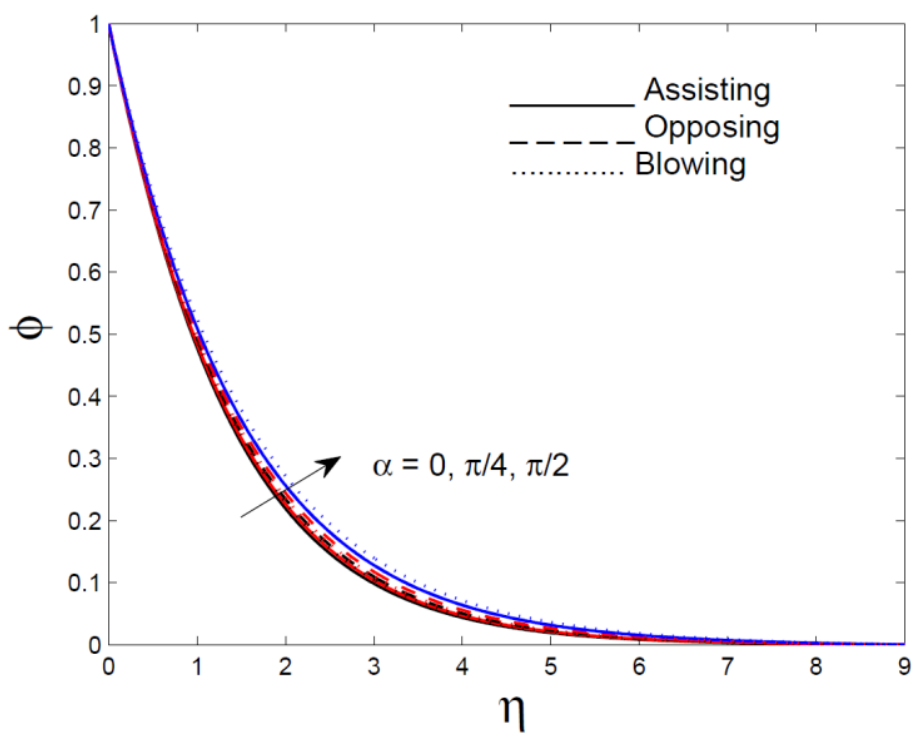

Fig. 13 Concentration distribution for different values of angle of inclination $(\alpha)$

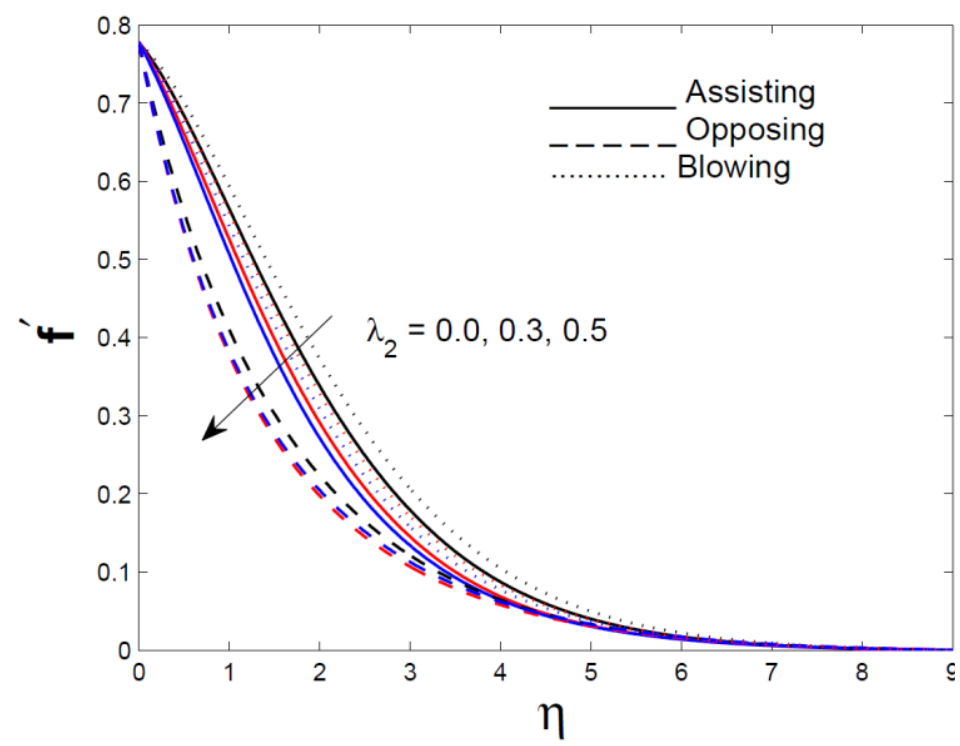

Fig. 14 Velocity profile for different values of thermal relaxation time $\left(\lambda_{2}\right)$
Figs. 11-13 exhibit the velocity, temperature and concentration profiles respectively for various values of angle of inclination $(\alpha)$. As increase in $\alpha$ from 0 to $\pi / 2$ through $\pi / 4$, the flow velocity decreases for all cases of assisting, opposing and blowing. It means that horizontal, inclines and vertical flows are decreased with increase in $\alpha$ (fig. 11). The depreciation flow velocity causes to enhance temperature and concentration distributions. Therefore, thermal and concentration boundary layer thickness are enhances for larger values of $\alpha$ as shown in figs. 12 and 13.

Figs. 14-16 represent the flow velocity, temperature and concentration profiles for different values of thermal relaxation time $\left(\lambda_{2}\right)$. The problem reduces to Fourier's heat conduction model for $\lambda_{2}=\frac{\lambda U_{0} e^{\frac{x}{L}}}{L}=0$. It is seen from fig. 14 that the flow velocity along the plate depreciates with increase in $\lambda_{2}$ from 0 to 0.5 through 0.3 . It is worth to mention from these results that fluid velocity results are more

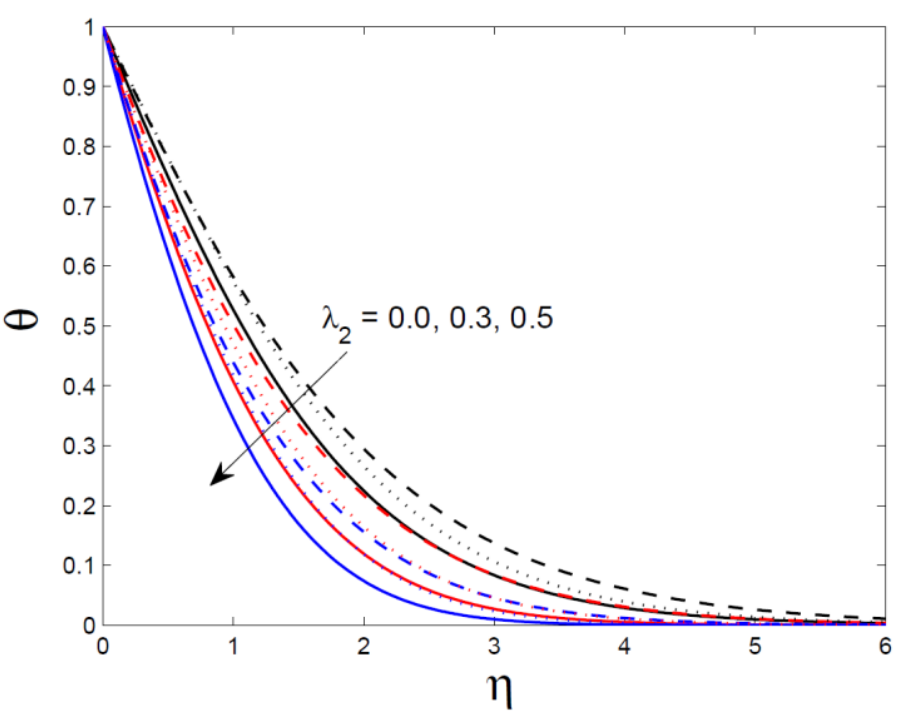

Fig. 15 Temperature distribution for different values of thermal relaxation time $\left(\lambda_{2}\right)$

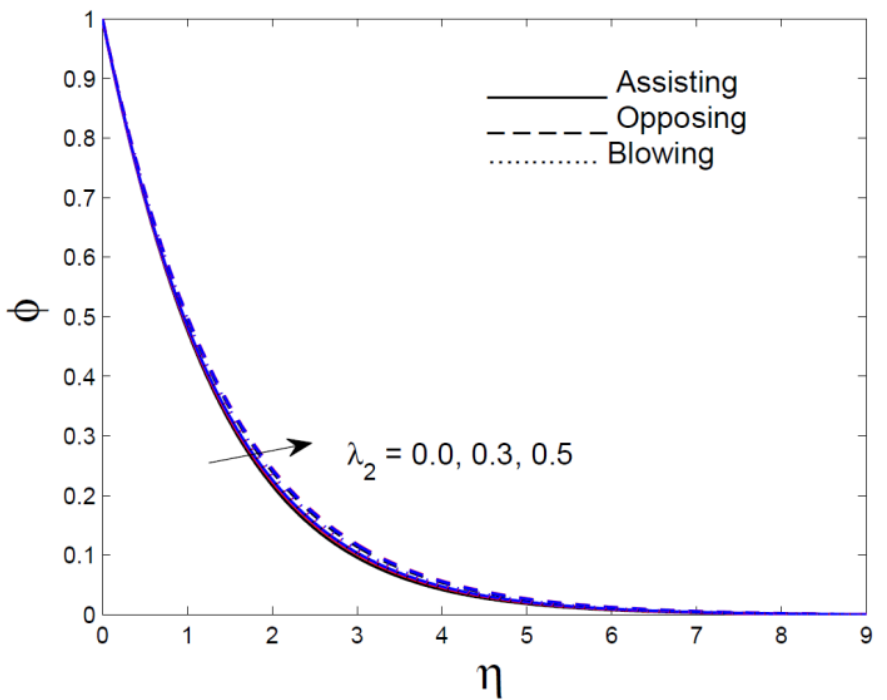

Fig. 16: Concentration distribution for different values of thermal relaxation time $\left(\lambda_{2}\right)$ 


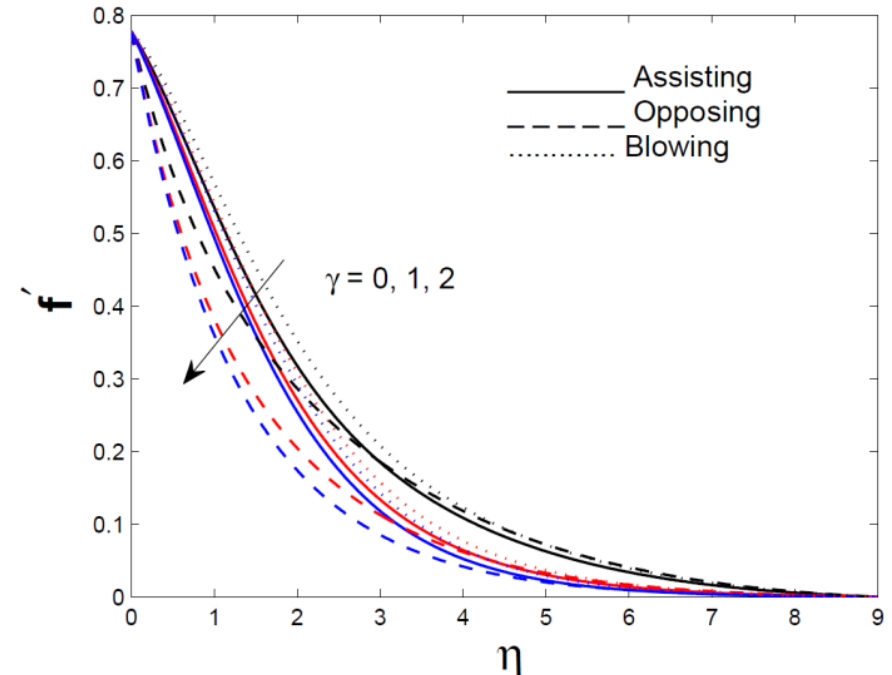

Fig. 17 Velocity profile for different values of the chemical reaction parameter $(\gamma)$

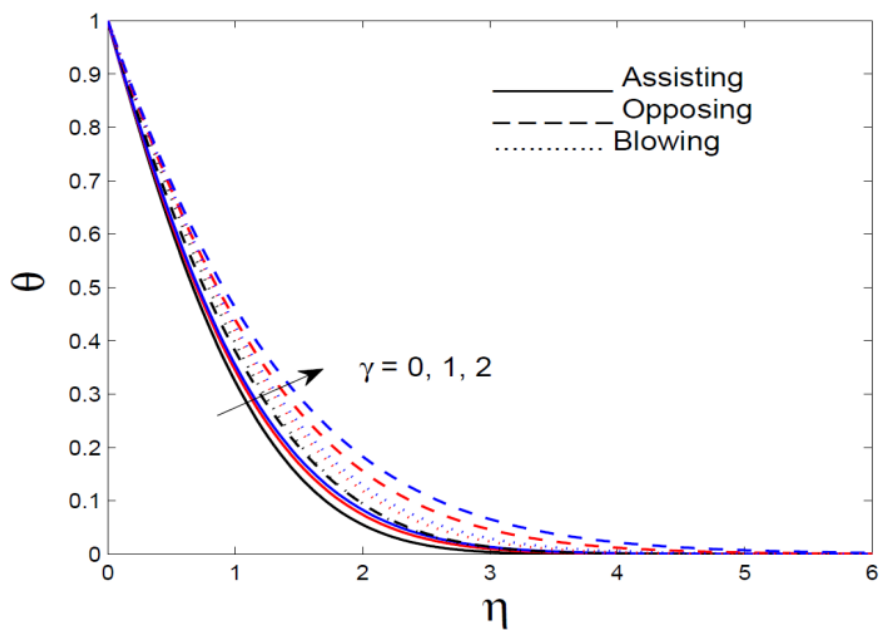

Fig. 18 Temperature distribution for different values of the chemical reaction parameter $(\gamma)$

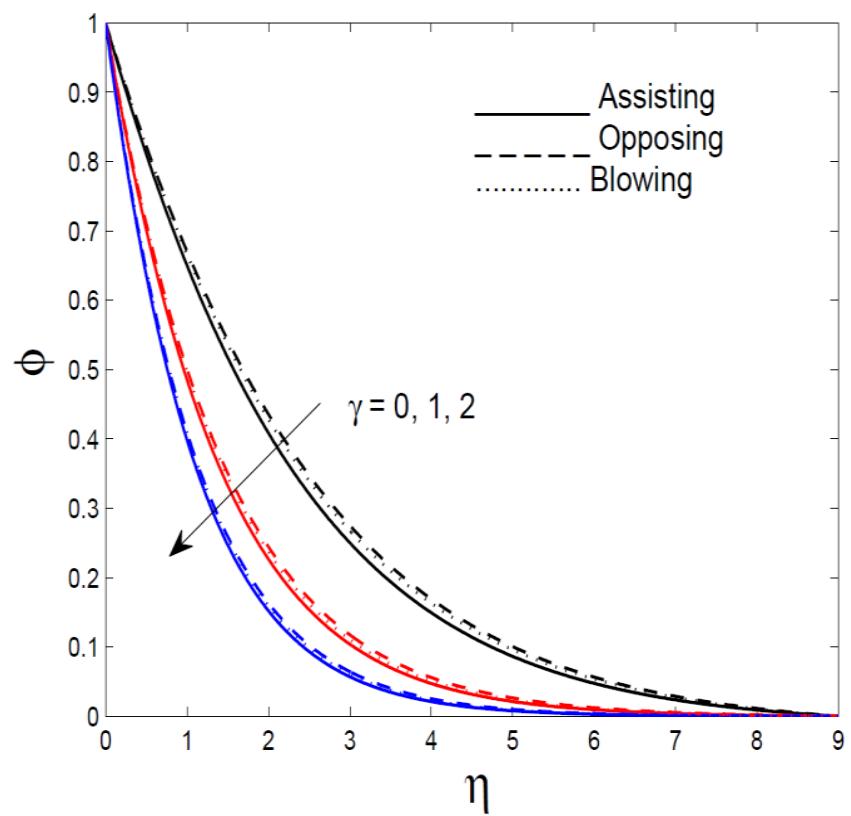

Fig. 19. Concentration distribution for different values of the chemical reaction parameter $(\gamma)$ dominated for Fourier heat flux model than Cattaneo-Christov heat flux model. Thus thickness of the momentum boundary layer reduces for all cases of assisting, opposing and blowing. The similar results have been observed for temperature field that is increase in $\lambda_{2}$ decelerates the thickness of thermal boundary layer. The opposite results are observed for concentration distribution as shown in fig. 16. The similar behavior for viscous fluid has been documented by Mustafa (2015).

Figs. 17-19 show the profiles of velocity, temperature and concentration respectively for various values of the chemical reaction parameter $(\gamma)$. As shown in fig 17, the fluid velocity decreased clearly with stiffer chemical reaction, that is Increase in $\gamma$ retards the flow velocity and therefore the thickness of momentum boundary layer is enhanced for all cases of assisting, opposing and blowing. As chemical reaction parameter presents in concentration equations, the results shows drastic change in concentration distribution compared to temperature distribution. Therefore, the result of temperature and concentration distributions shows opposite results. That is the thickness of thermal and concentration boundary layer increase and decrease respectively for larger values of $\gamma$ for all the cases of assisting, opposing and blowing. Similar behavior has been noticed by Mallikarjuna et.al (2016) for limiting cases.

Figs. $20-22$ represent the effects of velocity slip parameter (Sv) on flow velocity, temperature and concentration profiles respectively. The fluid velocity strongly decelerates near the surface as increase in Sv and transition is reported far from surface that is smooth increment has been observed in the boundary layer regime demonstrating the convergence of the numerical solution. The same behavior is reported by Bala Anki Reddy (2016). Fig. 21 shows that increase in Sv tends to enhance temperature field significantly, i.e. accelerates thermal boundary layer thickness for all cases of assisting, opposing and blowing. Concentration field increased as well smoothly with increase in Sv for all the cases of assisting, opposing and blowing. These trends were also analyzed by Ramachandra Prasad et.al (2013) for limiting cases.

Table 2 shows the values of skin friction coefficients, rate of heat and mass transfer for different values of $\beta, H, \lambda_{1}, \delta, \lambda_{2}, \gamma, S$ and $S v$. It is noticed from this table that skin friction coefficient found to increase for increasing values of $\beta, H, \delta, S v$ and decreasing values of $\lambda_{2}, \gamma$. Nusselt number (rate of heat transfer) values accelerated for larger values of $\beta, \delta$ and smaller values of $H, \lambda_{2}, \gamma$. Sherwood number values are enhanced with increase in $\beta, \gamma$ and decrease in $H, \delta, \lambda_{2}$. The rate of heat transfer increases for $\mathrm{Sv}<1$ while decreases for $\mathrm{Sv}>1$. The opposite behaviour has been reported for rate of mass transfer for different values of Sv.

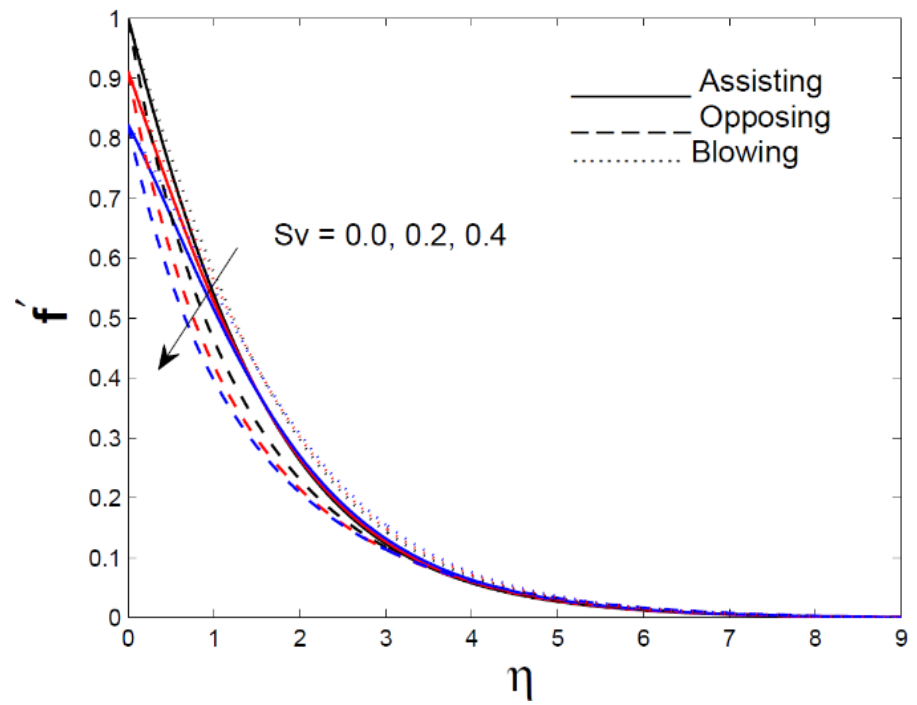

Fig. 20: Velocity profile for different values of the velocity slips parameter (Sv) 
Table 2 The values of skin friction coefficient, Nusselt number and Sherwood number for various values of $\beta, H, \lambda_{1}, \delta, \lambda_{2}, \gamma, S$ and $S v$

\begin{tabular}{|l|l|l|l|l|l|l|l|l|l|l|}
\hline$\beta$ & $\mathrm{H}$ & $\lambda_{1}$ & $\delta$ & $\lambda_{2}$ & $\gamma$ & $\mathrm{S}$ & $\mathrm{Sv}$ & $f^{\prime \prime}(0)$ & $-\theta^{\prime}(0)$ & $-\phi^{\prime}(0)$ \\
\hline 1 & 1 & 1 & 0.5 & 0.5 & 1 & 0.5 & 0.5 & -0.951597 & 1.407154 & 0.761082 \\
\hline 1.5 & 1 & 1 & 0.5 & 0.5 & 1 & 0.5 & 0.5 & -0.948582 & 1.428728 & 0.762418 \\
\hline 2 & 1 & 1 & 0.5 & 0.5 & 1 & 0.5 & 0.5 & -0.936328 & 1.436834 & 0.762751 \\
\hline 1 & 1.5 & 1 & 0.5 & 0.5 & 1 & 0.5 & 0.5 & -1.142080 & 1.364190 & 0.755402 \\
\hline 1 & 2 & 1 & 0.5 & 0.5 & 1 & 0.5 & 0.5 & -1.317132 & 1.325798 & 0.750545 \\
\hline 1 & 1 & 0.5 & 0.5 & 0.5 & 1 & 0.5 & 0.5 & -1.196490 & 1.369069 & 0.756493 \\
\hline 1 & 1 & 0.5 & 0.5 & 0.5 & 2 & 0.5 & 0.5 & -1.236027 & 1.352026 & 0.954526 \\
\hline 1 & 1 & 0.5 & 0.5 & 0.5 & 3 & 0.5 & 0.5 & -1.261932 & 1.341603 & 1.113977 \\
\hline 1 & 1 & 0.5 & 1 & 0.5 & 1 & 0.5 & 0.5 & -0.834423 & 1.450297 & 0.767635 \\
\hline 1 & 1 & 0.5 & 0.5 & 0.4 & 1 & 0.5 & 0.5 & -1.176362 & 1.223509 & 0.757418 \\
\hline 1 & 1 & 0.5 & 0.5 & 0.2 & 1 & 0.5 & 0.5 & -1.131815 & 0.952533 & 0.759691 \\
\hline 1 & 1 & 0.5 & 0.5 & 0.5 & 1 & 0.4 & 0.5 & -1.139495 & 1.206712 & 0.740844 \\
\hline 1 & 1 & 0.5 & 0.5 & 0.5 & 1 & 0.2 & 0.5 & -1.032603 & 0.947289 & 0.710515 \\
\hline 1 & 1 & 0.5 & 0.5 & 0.5 & 1 & 0.5 & 1 & -0.500008 & 1.136294 & 0.731843 \\
\hline 1 & 1 & 0.5 & 0.5 & 0.5 & 1 & 0.5 & 2 & 0.7145630 & 0.741356 & 0.679769 \\
\hline
\end{tabular}

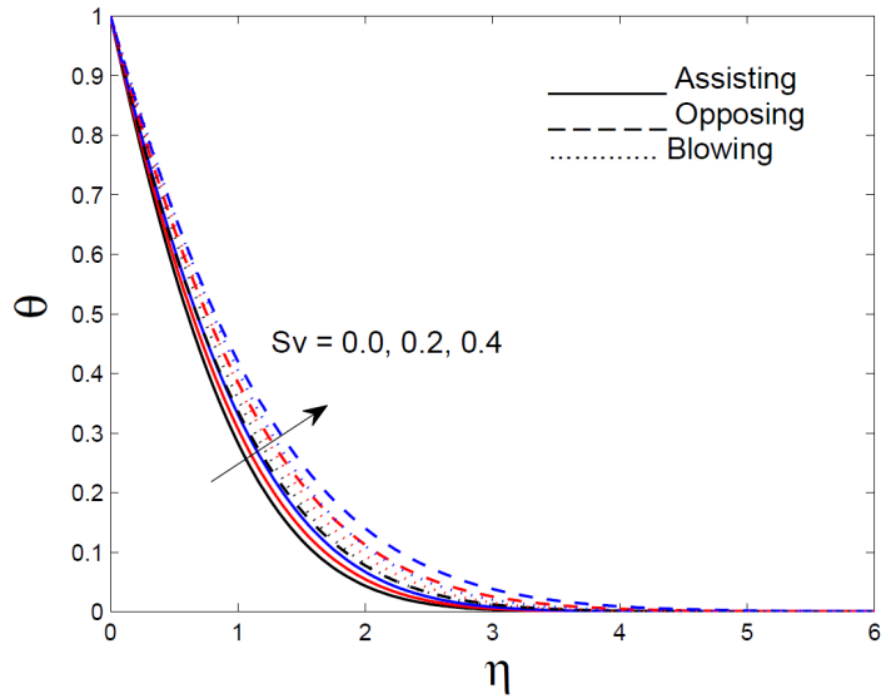

Fig. 21 Temperature distribution for different values of the velocity slips (Sv)

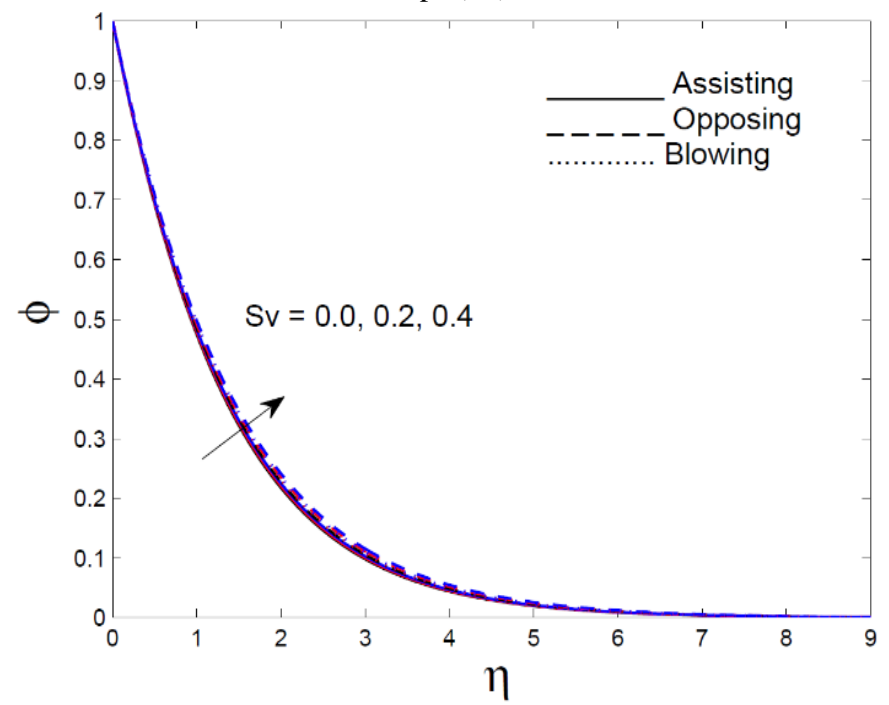

Fig. 22 Concentration distribution for different values of the velocity slips (Sv)

\section{CONCLUSIONS}

In this paper, velocity slip and chemical reaction effects are investigated on convective heat and mass transfer flow of a Casson fluid with Cattaneo-Christov Model from an inclined stretching sheet. The governing boundary equations are non-dimensionalized using similarity transformations. The numerical method has been employed to obtain the solutions of the resultant nonlinear ordinary differential equations. The values are presented graphically for different values of physical parameter on flow velocity, temperature and concentration fields and rate of heat and mass transfer. The conclusions of the results are:

- Increasing Casson fluid parameter tends to depreciates flow velocity while enhances temperature and concentration distributions, skin friction coefficient, rate of heat and mass transfer as well.

- Increase in Hartmann number retards the flow velocity, rate of heat and mass transfer and increase the values of temperature and concentration profiles.

- As increase in angle of inclination parameter, velocity decelerates while temperature and concentration profiles are accelerated.

- The effect of thermal relation of time is to decrease all the flow characteristics except the concentration profile.

- The momentum and solutal boundary layer thickness and skin friction coefficients and rate of heat transfer values are reduced with increase in chemical reaction parameter while it enhances temperature profile and rate of mass transfer results.

- Increase in velocity slip parameter leads to reduce the fluid velocity and rate of heat and mass transfer while enhances temperature and concentrations distributions and skin friction coefficient values.

\section{ACKNOWLEDGEMENTS}

One of the authors Dr. B. Mallikarjuna wishes to thank to B.M.S. College of Engineering, Bangalore-19, for giving support to made this paper.

\section{NOMENCLATURE:}

$U$ stretching velocity

$U_{0}$ reference velocity 


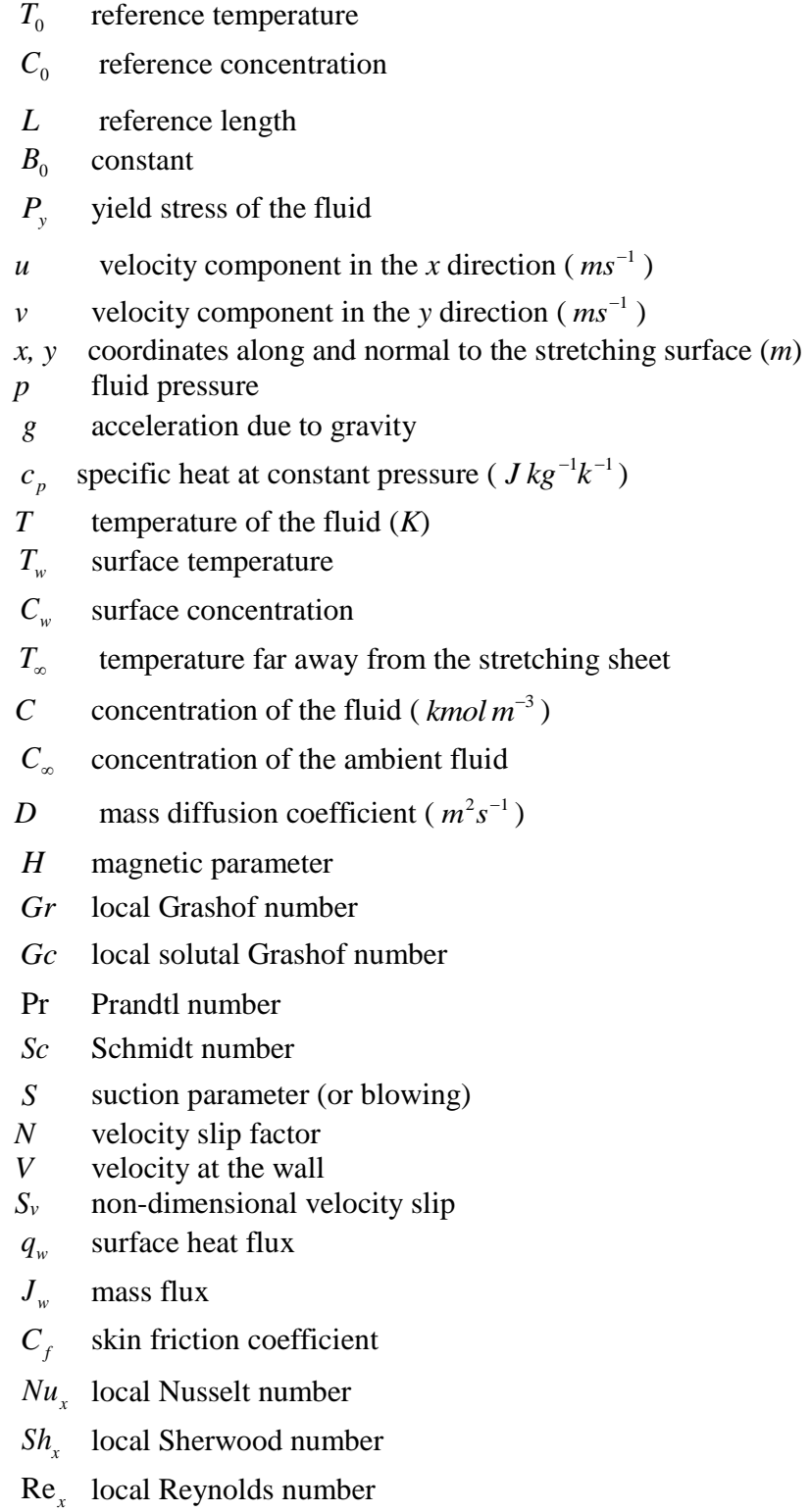

\section{Greek symbols}

$\mu_{B} \quad$ plastic dynamic viscosity of the non-Newtonian fluid

$\pi(i, j)^{\text {th }}$ component of the deformation rate

$\pi_{c} \quad$ critical value of this product based on the non-Newtonian model

$v \quad$ kinematic viscosity

$\mu \quad$ dynamic viscosity

$\rho \quad$ density of the fluid $\left(\mathrm{kg} \mathrm{m}^{-3}\right)$

$\beta \quad$ Casson Parameter

$\sigma \quad$ electrical conductivity

$\beta_{T} \quad$ coefficient of thermal expansion $\left(\mathrm{m}^{3} / \mathrm{kmol}\right)$

$\beta^{*} \quad$ coefficient of solutal expansion $\left(K^{-1}\right)$

$\alpha \quad$ inclination angle from the vertical direction

$\lambda$ buoyancy parameter

$\eta \quad$ similarity variable

$\delta \quad$ solutal buoyancy parameter

$\theta$ dimensionless temperature

$$
\begin{array}{ll}
\phi & \text { dimensionless concentration } \\
\Gamma & \text { chemical reaction rate }\left(\mathrm{kmol} \mathrm{m}^{-3}\right) \\
\gamma & \text { chemical reaction parameter } \\
\tau_{w} & \text { surface shear stress }\left(\mathrm{N} \mathrm{m}^{-2}\right)
\end{array}
$$

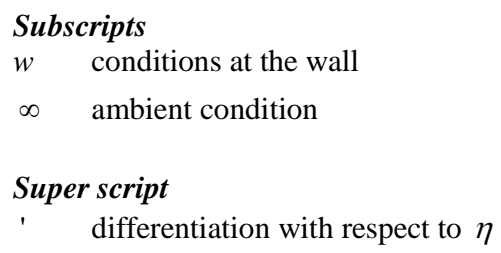

\section{REFERENCES}

Bala Anki Reddy P, 2016, "Magnetohydrodynamic Flow of A Casson Fluid Over an Exponentially Inclined Permeable Stretching Surface with Thermal Radiation and Chemical Reaction," Ain Shams Engineering Journal, 7(2), 593-602. https://doi.org/10.1016/j.asej.2015.12.010

Bhuvanavijaya R, RamachandraPrasad V, Mallikarjuna B and Anwar Beg, O, 2014, "Natural Convective Heat Transfer Flow of a NonNewtonian Second-grade Fluid Past an Isothermal Sphere," Computational Thermal Science, 6(5), 451-460. https://doi.org/10.1615/ComputThermalScien.2014011263

Cattaneo C. 2011, Sulla Conduzione Del Calore, In: Pignedoli A. (eds) "Some Aspects of Diffusion Theory," C.I.M.E. Summer Schools, 42, https://doi.org/10.1007/978-3-642-11051-1_5

Cebeci, T. and Bradshaw, P. 1984, "Physical and Computational Aspects of Convective Heat Transfer," Springer-Verlag publication.

Christov CI, 2009. " On Frame Indifferent Formulation of the MaxwellCattaneo Model of Finite- Speed Heat Conduction," Mechanics Research Communication, 36, 481-486.

https://doi.org/10.1016/j.mechrescom.2008.11.003

Dash RK, Mehta KN, Jayaraman G, 1996. "Casson Fluid Flow in a Pipe Filled with a Homogeneous Porous Medium,” Int J Eng Sci, 34, 114556.

https://doi.org/10.1016/0020-7225(96)00012-2

Fourier, JBJ, 1822, “Theorie Analytique De La Chaleur,” Paris.

Fung YC, 1984, Biodynamics Circulation, New York Inc.: SpringerVerlag

Han S, Zheng L, C Li and Zhang X, 2014. "Coupled Flow and Heat Transfer in Viscoelastic Fluid with Cattaneo-Christov Heat Flux Model," Applied Mathematics Letters; 38, 87-93.

https://doi.org/10.1016/j.aml.2014.07.013

Hayat T, Awais M, Sajid M, 2011. "Mass Transfer Effects on the Unsteady Flow of UCM Fluid over a Stretching Sheet," Int J Mod Phys $B, 25,2863-78$. https://doi.org/10.1142/S0217979211101375

Hayat T, Shehzad SH, Alsaed A, 2012. "Soret and Dufour Effects on Magnetohydrodynamic Flow of Casson Fluid," Appl Math Mech-Engl $E d, 33(10), 1301-12$. https://doi.org/10.1007/s10483-012-1623-6 
Hayat T, Shehzad SA, Alsaediz A, Alhothuali MS 2012. "Mixed Convection Stagnation Point Flow of Casson Fluid with Convective Boundary Conditions," Chin Phys Lett, 29, 114704-1-4. https://doi.org/10.1088/0256-307X/29/11/114704/meta

Hayat T, Farooq M, Alsaedi A and Falleh Al-Solamy 2015. "Impact of Cattaneo-Christov Heat Flux in the Flow over a Stretching Sheet with Variable Thickness," AIP ADVANCES, 5, 087159.

https://doi.org/10.1063/1.4929523

Hayat T, Muhammed T, Alsaedi A, Mustafa M, 2016, "A Comparative Study for Flow of Viscoelastic Fluids with Catteno-Chirstov Heat Flux," PLoS One. May-13, 11(5)

https://doi.org/10.1371/journal.pone.0155185

Ishak, A, 2011, "MHD Boundary Layer Flow Due To an Exponentially Stretching Sheet with Radiation Effect," Sains Malaysiana, 40, 2011, pp.391-395.

Mahantesh MN, Subhas Abel M, Jagadish T, 2010. "Heat Transfer in a Walter's Liquid B Fluid over an Impermeable Stretching Sheet with Non-uniform Heat Source/sink And Elastic Deformation," Commun Nonlinear Numer Simulat, 15, 1791-1802.

https://doi.org/10.1016/i.cnsns.2009.07.009

Mallikarjuna, B, Rashad, A. M, Ali. J. Chamkha, Hariprasad Raju, S, 2016, "Chemical Reaction Effects On MHD Convective Heat And Mass Transfer Flow Past A Rotating Vertical Cone Embedded In A Variable Porosity Regime," Afrika Matematika, 27(3-4), 645-665.

https://doi.org/10.1007/s13370-015-0371-1.

Mukhopadhyay S, Vajravelu K, and Van Gorder R.A, 2013, "Casson Fluid Flow and Heat Transfer at an Exponentially Stretching Permeable Surface," Journal of Applied Mechanics, Vol. 80, 054502-1-9. https://doi.org/10.1115/1.4023618
Mustafa M, 2015 “Cattaneo-Christov Heat Flux Model for Rotating Flow and Heat Transfer of Upper-Convected Maxwell Fluid," AIP Advances, 5, 047109.

Nadeem S, Zaheer S, Fang T, 2011, "Effects of Thermal Radiation on the Boundary Layer Flow of a Jeffery Fluid over an Exponentially Stretching Surface," Num Algor, 57, 187-205.

Nadeem S, Haq Rizwana UI, Lee C, 2012. "MHD Flow of A Casson Fluid over an Exponentially Shrinking Sheet," Sci Iran B, 19, 1550-3. https://doi.org/10.1016/j.scient.2012.10.021

Nagendramma V, Raju, C.S.K, Mallikarjuna, B, Shehzad, S.A, and Leelarathnam, A, 2018, "3D Casson Naofluid Flow over Slandering Surface in a Suspension of Gyrotactic Microorganisms with CattaneoChristov Heat Flux," Applied Mathematics and Mechanics, Article is in Press.

https://doi.org/10.1007/s10483-018-2331-6

Prasad KV, Pal D, Datti PS, 2009. "MHD Power-law Fluid and Heat Transfer over a Non-isothermal Stretching Sheet". Commun nonlinear Numer Simulat, 14, 2178-89.

https://doi.org/10.1016/j.cnsns.2008.06.021

RamachandraPrasad V, Subba Rao A and Anwar Beg, O, 2013, "Flow and Heat Transfer Of Casson Fluid from A Horizontal Circular Cylinder with Partial Slip in Non-darcy Porous Medium," Journal of Applied and Computational Mathematics, 2(2), 1000127.

Sanjayanand E, Khan SK, 2006. "On Heat and Mass Transfer in A Viscoelastic Boundary Layer Flow Over an Exponentially Stretching Sheet," Int J Thermal Sci, 45, 819-28.

https://doi.org/10.1016/j.ijthermalsci.2005.11.002 